\title{
Identifikasi Peran Keluarga Penderita dalam Upaya Penanganan Gangguan Jiwa Skizofrenia
}

\section{Identification of the Family Role to Handling Schizophrenia Patients}

\author{
Rosdiana \\ Fakultas Kesehatan Masyarakat Univesitas Widyagama Mahakam Samarinda \\ (anahanur@gmail.com)
}

\begin{abstract}
ABSTRAK
Skizofrenia merupakan suatu deskripsi sindrom dengan variasi penyebab dan perjalanan penyakit yang luas, serta sejumlah akibat yang tergantung pada perimbangan pengaruh genetik dan sosial budaya. Penelitian bertujuan mengidentifikasi peran keluarga penderita dalam penanganan penderita skizofrenia. Kualitatif dengan pendekatan fenomenologi melalui wawancara, observasi dan dokumentasi terhadap 6 informan. Hasil menunjukkan bahwa keluarga mampu membuat keputusan yang tepat dan memanfaatkan fasilitas kesehatan dengan mengantarkan penderita ke puskesmas atau rumah sakit walaupun jaraknya cukup jauh, tetapi keluarga memiliki asumsi yang salah, bahwa rumah sakit tempat penitipan yang baik bagi penderita, sehingga kurangnya dukungan keluarga saat penderita menjalankan program di rumah sakit jiwa. Keluarga belum mengetahui gejala, penyebab dan sejak kapan penderita mulai mengalami skizofrenia, keluarga juga tidak mengetahui cara merawat dan memodifikasi lingkungan agar mampu mendukung kesembuhan penderita skizofrenia. Kesimpulan dalam penelitian ini bahwa ketidaktahuan keluarga dalam memberikan dukungan saat penderita menjalankan program di rumah sakit jiwa, ketidaktahuan keluarga dalam mengenal, memahami, merawat dan memodifikasi lingkungan yang menyebabkan kekambuhan, bahkan semakin parah skizofrenia yang dialami oleh penderita di wilayah kerja Puskesmas Sebakung Jaya.
\end{abstract}

Kata kunci : Peran, keluarga, skizofrenia

\begin{abstract}
Schizophrenia is a description of the syndrome with a variety of causes and course of the disease are widespread, as well as some of the consequences that depend on the balance of genetic and socio-cultural influences. This study aims to identify the role of families of patients in Handling People with schizophrenia. Qualitative research method with phenomenology approach through interviews, observation and documentation to 6 informants. The results showed that families are able to make the right decisions and take advantage of the health facility by delivering the patient to the health center or hospital even though it was quite far away, but the family has a wrong assumption, that the hospital where care is good for patients, so the lack of family support when patients run the program in a mental hospital. Family didn't know the different causes, symptoms and since when the patient begins to experience schizophrenia, the families also do not know how to treat and modify the environment to be able to support the recovery people with of schizophrenia. The conclusion of this study are the ignorance of the family in providing support while the person running the program in a psychiatric hospital, ignorance family in the know, understand, maintain and modify the environment that leads to relapse, even worse schizophrenias experienced by patients in Sebakung Jaya Health Center.
\end{abstract}

Keywords : Role, family, schizophrenia

Copyright (C) 2018 Universitas Hasanuddin. This is an open access article under the CC BY-NC-SA license

(https://creativecommons.org/licenses/by-nc-sa/4.0/).

DOI : http://dx.doi.org/10.30597/mkmi.v14i2.3787 


\section{PENDAHULUAN}

Skizofrenia merupakan sekelompok reaksi psikotik yang mempengaruhi berbagai individu termasuk berpikir dan komunikasi, menerima dan menginterprestasikan realitas, merasakan dan memajukan emosi serta perilaku dengan sikap yang tidak bisa diterima secara sosial. Skizofrenia pada umumnya ditandai oleh penyimpangan mental dan karakteristik dari pikiran dan persepsi, serta oleh efek yang tidak wajar/inappropriate atau tumpul/ blunted..$^{1,2}$

Laporan organisasi kesehatan dunia (World Health Organization/WHO) pada 2010 tentang Global Burden Disease menyebut, kini telah terjadi perubahan jenis penyakit yang menimbulkan beban bagi negara secara global. Sebelumnya, WHO menyebut kasus kematian ibu dan anak paling besar membebani negara, tetapi kini bergeser ke penyakit kronis, termasuk penyakit jiwa berat, misalnya skizofrenia. Penderita gangguan psikis dengan diagnosis skizofrenia tahun 2010 kurang lebih 24 juta jiwa di seluruh dunia. Dari jumlah 24 juta jiwa tersebut 1.928 .663 juta jiwa tercatat berada di Indonesia, dengan kasus skizofrenia. Dalam laporan tersebut terdapat dalam pengkajian data di Indonesia dengan kasus skizofrenia mencapai $2,5 \%$ dari total penduduk Indonesia. ${ }^{3}$

Menurut Bagus Utomo sebagai Pendiri Rumah Komunitas Peduli Skizofrenia Indonesia (KPSI), mengemukakan bahwa dari 34 provinsi di Indonesia, hingga kini masih 7 provinsi yang belum memiliki rumah sakit jiwa. Jumlah psikiaternya juga minim, dengan perbandingan 1 banding 400 ribu. Penanganan atau proses pemulihan pasien dengan gangguan jiwa, salah satunya skizofrenia di Indonesia masih buruk. Proses penanganan Orang Dengan Skizofrenia (ODS) memerlukan penanganan yang lama, mulai dari perawatan di rumah sakit, pemberian obat, sampai dukungan sosial, keluarga dan masyarakat. Misalnya, seorang pasien sudah mendapatkan obat dengan baik, proses pemulihan di rumah sakit berjalan bagus, tetapi pada saat di rumah tidak didukung keluarga dan lingkungan, maka bisa jadi pasien akan mengalami kekambuhan. Oleh sebab itu, proses pemulihan penyakit ini tahunan. Oleh karena prosesnya lama, maka butuh ketekunan dan kesabaran dari keluarga. ${ }^{4}$

Fenomena lain yang menarik adalah adanya kecenderungan keluarga/masyarakat untuk menjadikan Rumah Sakit Jiwa sebagai tempat pembuangan bagi orang dengan gangguan jiwa. Setelah diantar, keluarga tidak pernah membesuk lagi, pasien dianggap sudah menjadi tanggungjawab petugas rumah sakit jiwa, sedangkan keluarga tidak mau tahu tentang keadaan pasien. Sehingga, terkadang ditemukan pasien di Rumah Sakit Jiwa yang telah menjadi warga disana lebih dari sepuluh tahun tanpa pernah diketahui alamat dan keluarganya. ${ }^{5,6}$

Puskesmas Sebakung Jaya adalah salah satu puskesmas yang berada di wilayah selatan Kabupaten Penajam Paser Utara yang berbatasan langsung dengan wilayah Kabupaten Paser, sehingga jangkauan jarak baik ke Rumah Sakit Umum Daerah Penajam maupun ke Rumah Sakit Jiwa Samarinda relatif jauh. Berdasarkan Peraturan Menteri Kesehatan Republik Indonesia Nomor 43 tahun 2016 tentang Standar Pelayanan Minimal Bidang Kesehatan (SPM), merupakan acuan bagi Pemerintah Daerah Kabupaten/Kota dalam penyediaan pelayanan kesehatan yang berhak diperoleh setiap warga secara minimal. Salah satu jenis layanan Standar Pelayanan Minimalnya adalah pelayanan kesehatan orang dengan gangguan jiwa berat. Atas dasar itulah Puskesmas Sebakung Jaya menjadikan pelayanan kesehatan orang dengan gangguan jiwa berat menjadi usaha kesehatan wajib. Data penyakit skizofrenia dengan kriteria gangguan psikotik dan neurotik, tahun 2014 penderita penyakit skizofrenia 4 pasien, tahun 2015 penderita penyakit skizofrenia 7 pasien, tahun 2016 menunjukan peningkatan penderita penyakit skizofrenia menjadi 10 pasien. Diagnosa skizofrenia berjumlah 10 pasien di antaranya mengalami halusinasi, depresi berat, waham, dan kasus paling serius di antaranya yaitu penderita skizofrenia melakukan percobaan bunuh diri. ${ }^{7,8}$ Oleh karena itu, penelitian dilakukan untuk mengidentifikasi peran keluarga penderita dalam upaya penanganan gangguan jiwa skizofrenia.

\section{BAHAN DAN METODE}

Penelitian menggunakan metode penelitian kualitatif dengan pendekatan fenomenology. Dilaksanakan di wilayah kerja Puskesmas Sebakung Jaya, pada September - Oktober 2017. Jumlah informan 6 orang yang terdiri dari 3 orang 
keluarga (orang tua penderita skizofrenia), 1 orang petugas kesehatan Puskesmas Sebakung Jaya, 1 orang kepala desa dan 1 orang petugas Rumah Sakit Jiwa Atma Husada Samarinda. Data yang diperoleh melalui wawancara mendalam (indepth interview), observasi dan dokumentasi terhadap keluarga dan penderita skizofrenia. ${ }^{9,10,11}$

Teknik analisis data yang digunakan adalah pola intraksi secara interaktif dan berlangsung secara terus menerus sampai tuntas, sehingga data yang diperoleh jenuh. Miles and Huberman (1984) dalam Sugiyono,${ }^{10}$ mengemukakan bahwa pola interaksi analisis data dengan tiga prosedur yaitu: Tahap reduksi data sebagai proses pemilihan, pemusatan, perhatian pada penyederhanaan, pengabstarakan dan transformasi data kasar yang muncul dari catatan-catatan tertulis di lapangan, data dihimpun dari berbagai sumber di lapangan, disederhanakan dan disimpulkan. ${ }^{10}$

Tahap penyajian data dimaksudkan sebagai sekumpulan informasi tersusun, yang memberikan kemungkinan adanya penarikan kesimpulan dan pengambilan tindakan. Dengan melihat penyajian data peneliti dapat memahami apa yang sedang terjadi dan apa yang harus dilakukan. Hal ini memudahkan bagi penulis, melihat gambaran secara keseluruhan atau bagian-bagian tertentu dari data penelitian, sehingga data tersebut bisa ditarik kesimpulan. ${ }^{10}$

Tahap kenarikan kesimpulan/verifikasi, merupakan satu kegiatan dari konfigurasi yang utuh selama penelitian berlangsung, sedangkan verifikasi merupakan kegiatan pemikiran kembali yang melintas di pemikiran penganalisis selama penulis mencatat, atau suatu tinjauan ulang pada catatan-catatan lapangan serta tukar pikiran diantara teman sejawat untuk mengembangkan "intersubyektif" dengan kata lain makna yang muncul dari data harus diuji kebenarannya, kekokohannya dan kecocokannya (validitasnya). ${ }^{10}$

\section{HASIL}

Berdasarkan hasil wawancara yang telah dilakukan penulis, keluarga penderita tidak mengetahui, memahami dan mengenal gejala-gejala dan pengertian gangguan jiwa/skizofrenia, dan juga tidak mengetahui penyebab anaknya mengalami skizofrenia seperti yang diungkapkan informan berikut ini: "gila itu ya.. diajak ngomong tidak nyambung, suka melamun, jarang keluar rumah, pokoknya aneh lah tidak nyambung, ditanyain diam, makan juga sering lupa."

(W.A.S.2)

Penyebab skizofrenia berdasarkan informasi dari 3 informan berbeda-beda. Berdasarkan asumsi orang tua dari 3 penderita, anaknya skizofrenia bukan karena keturunan, karena belum ada orang tua atau keturunan mereka yang skizofrenia sebelumnya. Penyebab skizofrenia pada anaknya dikarenakan anaknya sering jatuh atau sering dipukulin teman sepermainnya dibagian kepala waktu kecil, informan lain mengatakan, karena banyak masalah dalam keluarga, dan ada juga yang mengatakan anaknya stress menghadapi tugas kuliah. Berdasarkan kutipan wawancara sebagai berikut:

"Ya awalnya itukan rumah tangga ba-nyak masalah, apa-apa itu minta diturutin, pokoknya disuruh nurutin dia terus, padahal saya itu sudah ku turutin, apa-apa itu ku turutin, jalan ku turutin, mau ke ladang orang dua ya kuturutin, tetapi dia suka ngelamun aja, jadi jarang keluar rumah, pokoknya aneh lah gak nyambung, ditanyain diam, makan juga sering lupa."

(W.A.S.2)

"he'eh jadi waktu kecil itu sering jatuh itu, sering mainan sama temannya, namanya anak kecil kadang pegang angklong kayu dipukulkan gitu sama temannya tau-tau ada luka gitu kan, mungkin juga banyak pikiran dan banyak ngelamun."

Berdasarkan hasil wawancara penulis terhadap 3 informan, yaitu orang tua penderita dalam pemanfaatan pelayanan kesehatan terhadap anaknya yang mengalami skozifrenia sudah baik dan tepat karena orang tua pendertia sering mengantarkan anaknya ke puskesmas untuk konsultasi dengan petugas kesehatan tentang masalah yang dihadapi oleh anaknya, bahkan 2 dari tiga informan dirujuk ke Rumah Sakit Jiwa Samarinda. Salah satu dari dua informan diizinkan kembali dan tinggal bersama keluarganya setelah dirawat 
selama 3 bulan di Rumah Sakit Jiwa Atma Husada Samarinda. Berdasarkan kutipan wawancara sebagai berikut:

"oh nggak mau dibawa ke puskesmas, la wong aku ki gak loro kok arep digowo berobat, akuki nggak loro, akuki nggak sakit, gitu katanya, tetapi tetap saya usahakan supaya dia mau berobat, kontrol begitu. Lama-lama baru dia mau."

Berdasarkan hasil triangulasi dari informan selaku petugas kesehatan dan pemegang program, menyatakan bahwa:

"Iya betul rutin kontrol ke Puskesmas kalau obatnya habis atau ada masalah lainnya, dan ada juga yang dirujuk ke RSJ Atma Husada Samarinda karena skizonya uda parah."

(W.C.PK.19)

Keluarga atau orang tua belum mampu merawat anaknya yang skizofrenia. Berdasarkan hasil wawancara dan observasi penulis terhadap 3 orang tua penderita dalam merawat anaknya masih terikut emosi dan beranggapan bahwa, selaku orang tua sudah banyak berkorban merawat dan menjaga pada waktu kecil hingga besar dan biaya juga sudah banyak yang dikeluarkan untuk biaya sekolah sampai ke bangku kuliah, dan biaya keperluan lainnya, dan sekarang masih menyusahkan bahkan membuat malu kelurga, seperti yang diungkapkan informan berikut ini:

"Maunya ya marah, tadinya ya marah, ya gimana merasa anaknya sudah dibiayain jadinya kayak gini ya kesal, jengkel gitu, pernah bapaknya mukul. Nah sadarnya saya itu setelah saya bawa ke Jawa, saya dikasih tau sama keluarga saya katanya ya sudah jadi nasibmu kayak gitu ya diterima, sabar. Akhirnya saya bisa terima, ya Alhamdulillah, tinggal kasi pengertian ke bapaknya pelan-pelan"

(W.A.I.12)

"Dia nggak mau kalau dimandikan, maunya mandi sendiri dan menyisir rambut sendiri cuma yaitu kadang dia mainan lagi sambil jalan, nah sekarang jalannya musim debu jadi ya kotor lagi dan rambutnya kusut lagi."

(W.A.I.22)

"lah iya, kita mau gak mau bersihkan rumah sendiri. waktu disini iya, makanya dibawa kesana. Kan disana gak ada yang tau, nah kadang dibawa kesini lagi sering ke belakang karena mungkin sering diolokin, dia sering ke belakang makanya saya susah jagainnya."

(W.A.I.15)

"Rutin obatnya minum 2 kali sehari harus digerus dulu terus kasih gula ya kita awasi."

(W.A.S.13)

Berdasarkan hasil observasi bahwa keluarga telah berusaha membangun kesadaran untuk menerima keadaan penderita. Namun, belum mampu merawat secara paripurna terutama dalam menjaga kebersihan penderita agar tidak menimbulkan penyakit-penyakit lainnya terutama penyakit kulit atau penyakit pernapasan yang disebabkan oleh debu. Kondisi penderita khususnya kebersihan individu memprihatinkan, rambut yang acakacakan, kuku tangan dan kaki cukup panjang dan kotor, pakaian yang digunakan kotor dan berbau. Bahkan ada 1 penderita kamarnya dipisahkan dari anggota keluarga yang lain, dan kondisi kamarnya tidak terurus, kotor, sampah berserakan dan berbau, sebagai tanda kurang diperhatikan.

Berdasarkan hasil wawancara dan observasi penulis, ketidak mampuan keluarga dalam memodifikasi lingkungan sosial, tempat tinggal dan sekitarnya yang menyebabkan penderita bukan kunjung sembuh bahkan semakin parah dari hari ke hari. Hal ini disebabkan keyakinan kelurga akan kesembuhan penderita skizofrenia sangat rendah, bahkan ada informan yang tidak memiliki harapan akan kesembuhan anaknya. Selain itu, keluarga juga tidak memiliki banyak waktu untuk mengurusi penderita, bahkan sering penderita hanya ditinggal sendiri di rumah dan dikuncikan pintu dari luar, seperti yang diungkapkan informan berikut ini:

"iya pokoknya apa-apa itu tidak mau, jadi akhirnya ya kita biarkan saja dia mau buat 
apa yang penting di dalam kamarnya."

(W.A.S.15)

\section{PEMBAHASAN}

Keluarga adalah lingkungan terdekat dengan penderita skizofrenia. ${ }^{12,13}$ Keluarga yang tidak dapat beradaptasi dengan penderita akan stres, sehingga tidak dapat menjalankan fungsinya dengan baik, termasuk fungsi perawatan keluarga/orang tua terhadap penderita. ${ }^{14}$ Pengetahuan keluarga dan orang tua penderita, tidak mengetahui awal mula penderita mengalami skizofrenia, hal ini disebabkan ketidaktahuan tentang gejala, penyebab skizofrenia serta kurangnya kepedulian keluarga dalam memahami dan mau mengerti kondisi penderita. Kondisi keluarga/orang tua penderita sudah cukup disibukkan dengan rutinitas sehari-hari, mencari nafkah untuk memenuhi kebutuhan keluarganya.

Berdasarkan hasil wawancara dan observasi penulis terhadap 3 keluarga penderita, bahwa penderita pada informan 1 (S) dalam struktur keluarga adalah seorang Ayah atau Kepala keluarga, jumlah anak 8 orang, jarak kelahiran setiap anak tidak lebih dari 3 tahun. Pendidikan terakhir penderita adalah Sekolah Dasar (SD). Sumber penghasilan untuk memenuhi biaya hidup keluarga dengan bertani, jumlah sawah 1 hektar dan jumlah hasil panen yang tidak menentu. Sedangkan hasil observasi pada informan 2 (I) bahwa status penderita adalah anak pertama dari 5 bersaudara. Pekerjaan orang tua mengelola kebun karet milik orang lain, hasilnya di bagi sesuai perjanjian dengan pemilik kebun. Usia penderita 21 tahun dan menderita skizofrenia sejak usia 19 tahun saat duduk dibangku kuliah. Informan 3 (D) adalah anak ke dua dari 4 bersaudara. Usia penderita 27 tahun dan menderita skizofrenia sejak usia 20 tahun, pendidikan terakhir tamat Sekolah Lanjut Tingkat Atas (SLTA). Pekerjaan orang tua mengelola kebun kelapa sawit.

Rutinitas sehari-hari keluarga dari 3 penderita semuanya mengelola kebun kelapa sawit, kebun karet dan mengelola sawah. Setiap hari keluarga penderita mulai menjalankan aktivitasnya, seperti berangkat ke kebun dari jam 6.30 atau 7.00, karena rata-rata jarak tempuh 30 hingga 45 menit, pada pukul 17.00 atau 18.00 keluarga/orang tua (Bapak dan Ibu) penderita baru pulang ke rumah berkumpul bersama keluarga. Kondisi lelah, letih dan lesu sepulang dari bekerja, dihadapkan dengan kondisi rumah tangga yang tidak terurus, tuntutan anak-anak begitu banyak merupakan pencetus stres dan depresi.

Penyebab penderita mengalami skizofrenia ialah karena psikologis dan sosial, adanya trauma yang bersifat kejiwaan, adanya hubungan orang tua-anak yang patogenik, serta interaksi yang patogenik dalam keluarga. Sementara itu, faktor yang paling utama dari penyebab penderita mengalami skizofrenia yaitu interaksi antara anggota keluarga, sehingga ketika salah satu anggota keluarga mempunyai masalah tidak ada yang memahami dan tidak bercerita tentang masalah yang dialami, akibatnya menimbulkan kurangnya rasa percaya antara sesama anggota keluarga, membuat beban dalam pikiran menumpuk sehingga solusi untuk penyelesaian masalah tidak ada maka terjadilah depresi berat, rasa malu, rasa salah dan akhirnya perilaku penderita berubah tidak seperti biasa, suka menyendiri, berbicara sendiri, teriak dan melakukan hal-hal yang tidak normal lainnya. ${ }^{15,16}$

Perilaku atau tindakan keluarga penderita sudah tepat dan mampu memutuskan dalam pemanfaatan pelayanan kesehatan yang tepat bagi penderita, dengan membawa penderita ke dokter atau petugas kesehatan. Namun, fungsi keluarga dalam memberikan dukungan saat penderita menjalankan program terapi untuk sembuh saat dirawat di Rumah Sakit Jiwa belum maksimal. ${ }^{17,18,}$

Orang tua penderita menyerahkan sepenuhnya kepada pihak rumah sakit untuk kesembuhan penderita. Berdasarkan hasil triangulasi sumber dari petugas kesehatan di Rumah Sakit Jiwa Atma Husada Samarinda. Bahwa, orang tua informan 2 (I) hanya dua kali datang selama anaknya dirawat di Rumah Sakit Jiwa, yaitu; saat membawa surat rujukan dari puskesmas, sekaligus mengantar anaknya dan menyelesaikan semua administrasi pendaftaran dan saat menjemput pulang saat anaknya sudah bisa diperbolehkan untuk pulang. ${ }^{19,20,21}$

Kemampuan keluarga dalam merawat penderita masih kurang karena badan penderita masih kotor dan berbau, kuku kaki dan tangan panjang dan penuh kotoran, rambut terurai kusut, kotor dan bau, kondisi kamar penderita kotor, sampah berserakan, berbau dan tidak rapi. Walaupun keluarga sudah berusaha menerima kenyataan bah- 
wa sudah nasibnya memiliki anggota keluarga yang skizofrenia, tetapi belum sepenuhnya mampu mengurus dan merawat penderita.

Hal ini disebabkan rutinitas sehari-hari dalam mencari nafkah untuk keluarga. Selain itu, keluarga juga tidak mempunyai harapan akan kesembuhan penderita. Keluarga beranggapan bahwa penyakit ini akan dialami oleh penderita seumur hidupnya. Walaupun petugas kesehatan telah menjelaskan, bahwa ada harapan untuk sembuh seperti semula bagi penderita skizofrenia, jika penderita mendapatkan dukungan dari keluarganya. Oleh karena banyaknya contoh atau bukti yang dilihat, kehidupan skizofrenia di wilayah kerja Puskesmas Sebakung Jaya tidak ada yang sembuh, bahkan makin parah sakitnya hingga ajal menjemput. Dalam hal ini petugas kesehatan harus lebih meningkatkan kinerjanya dalam memberikan asuhan keperawatan kepada penderita gangguan jiwa khususnya dalam memberikan konseling kepada keluarga untuk merawat anggota keluarga yang mengalami gangguan jiwa. ${ }^{22,23}$

Ketidakmampuan keluarga penderita dalam memodifikasi lingkungan, baik fisik, sosial, psikologi yang menyebabkan penderita semakin parah dari hari ke hari. Keluarga penderita tidak mengetahui tentang pentingnya interaksi yang baik antara anggota keluarga, dan saling memahami dan mengerti satu sama lain sehingga komunikasi antara keluarga terasa aman, nyaman dan ketika ada masalah keluarga menjadi tempat yang baik untuk bercerita dan menjadi pendengar yang baik serta memberikan solusi dari masalah yang dihadapi. ${ }^{24}$

Keluarga penderita juga tidak mengetahui dan memahami tentang menciptakan lingkungan kondusif yang bisa mempengaruhi dan membantu kesembuhan penderita Skizofrenia. Demikian juga, dengan tetangga dan masyarakat yang berada disekitar penderita, tidak mengetahui tentang cara memberikan dukungan sosial terhadap penderita. Masyarakat yang ada di wilayah Puskesmas Sebakung Jaya masih kuat akan stigma buruk tentang penderita skizofrenia. Misalnya, saat penderita jalan-jalan keluar rumah, masih banyak yang mengganggu atau mengolok-olok sehingga penderita tidak merasa nyaman dan terkadang emosinya memuncak/marah, kondisi seperti inilah yang semakin memperparah penderita. Dengan adanya kondisi sosial seperti ini, sehingga pentingnya dilakukan penyuluhan yang komprehensif kepada masyarakat melalui pemberdayaan masyarakat, keterlibatan toko masyarakat dan kader kesehatan, sehingga masyarakat bisa mendapatkan pemahaman yang baik dan benar bagaimana cara memberikan dukungan sosial kepada penderita agar cepat sembuh. ${ }^{25,26,27}$

\section{KESIMPULAN DAN SARAN}

Pengetahuan keluarga dan orang tua penderita, tidak mengetahui awal mula penderita mengalami skizofrenia, hal ini disebabkan ketidaktahuan informan tentang gejala, penyebab skizofrenia serta kurangnya kepedulian keluarga dalam memahami dan mau mengerti kondisi penderita. Perilaku atau tindakan keluarga penderita sudah tepat dan mampu memutuskan dalam pemanfaatan pelayanan kesehatan yang tepat bagi penderita. Ketidakmampuan keluarga dalam merawat penderita, menyebabkan badan penderita kotor dan berbau, kuku kaki dan tangan panjang dan penuh kotoran, rambut terurai kusut kotor dan berbau, kondisi kamar penderita kotor, sampah berserakan, berbau dan tidak rapi. Ketidakmampuan keluarga penderita dalam memodifikasi lingkungan, baik fisik, sosial, psikologi yang menyebabkan penderita semakin parah dari hari ke hari. Hasil penelitian ini menyarankan agar petugas kesehatan harus lebih meningkatkan kinerjanya dalam memberikan asuhan keperawatan kepada penderita skizofrenia, dan memberikan penyuluhan yang komprehensif kepada keluarga penderita dan masyarakat agar mendapatkan pemahaman yang baik dan benar tentang cara memberikan dukungan sosial, psikologi dan materi kepada penderita agar cepat sembuh.

\section{DAFTAR PUSTAKA}

1. Departemen Kesehatan RI. Jakarta: Bina Kesehatan Jiwa; 2013.

2. Ascobat, G.Tinjauan Kesehatan Jiwa dari Aspek Ekonomi. Jakarta: Rineka Cipta; 2010.

3. WHO. Global Burden Disease [Online] 05 Januari 2011., [diakses 05 Januari 2017]. Available at: https://apps.who.int/nut/db bfd. htm.

4. Bagus, U. Penanganan dan Proses Pemulihan Pasien dengan Gangguan Jiwa. Jakarta; 2011. 
5. Moersalin 2009. Ketika Gubernur ke Rumah Sakit Jiwa [Online]. 2009. Available http:www.harian-aceh.com.

6. Rumah Sakit Atma Husada. Profil Rumah Sakit Atma Husada: Samarinda; 2014

7. Puskesmas Sebakung Jaya. Profil Puskesmas Sebakung Jaya: Samarinda; 2016

8. Dinas Kesehatan Kabupaten Penajam Paser Utara. Profil Kesehatan Kabupaten Penajam Paser Utara. Penajam; 2015.

9. Bungin, B. Analisis Data Penelitian Kualitatif, Pemahaman Filosofis dan Metodologis Ke Arah Penguasaan Model Aplikasi. Jakarta: PT Rajawali Pers; 2016.

10. Notoatmodjo, S. Metodologi Penelitian Kesehatan. Jakarta : Rineka Cipta; 2010.

11. Saryono. \& Anggraeni, M.D. Metode Penelitian Kualitatif dan Kuantitatif. Yogyakarta: Nuha Medika; 2013

12. Fadli, S.M. \& Mitra. Pengetahuan dan Ekspresi Emosi Keluarga serta Frekuensi Kekambuhan Penderita Skizofrenia. Jurnal Kesehatan Masyarakat Nasional 2013;7(10): 466-470.

13. Bishop, M \& Greeff, A.P. Resiliensi in Families in Wich A Member Has Been Diagnosed With Schizofrenia. Journal of Psychiatric and Mental Health Nursing. 20015;22: 463-471.

14. Nurmaela., Suryani \& Imas, R. The Relation Of The Family Resilience With Subtance On Skizofrenia Patients in The Psikiatri Unit. Jurnal keperawatan Padjadjaran. 2018;6(1): 18-24.

15. Soeyatno. Kesehatan Mental, Konsep, Cakupan dan Perkembangannya. Yogyakarta: CV. Andi Offset; 2013.

16. Buse, K. Making Health Policy: Understanding Public Health, Second Edition. London: Open University Press Me Graw Hill Education: 2009.
17. Copel, L. Kesehatan Jiwa dan Psikiatri Pedoman Klinis Perawat Edisi 2. Jakarta : EGC; 2017.

18. Notoatmodjo, S. Ilmu Perilaku Kesehatan, Jakarta : Rineka Cipta; 2010.

19. Undang-Undang Republik Indonesia No 18 tahun 2014. Tentang Kesehatan Jiwa. Jakarta: Kementrian Kesehatan.

20. Undang-Undang Republik Indonesia No 36 Tahun 2014. Tentang Tenaga Kesehatan: Kementrian Kesehatan.

21. Mahar, A., Ika, N \& Bambang H.Y.. Evektivitas Pelayanan Selama Penerapan Clinical Pathway Skizofrenia Rawat Inap di RSUD DR.Sardjito Yogyakarta. Manajemen Pelayanan Kesehatan. 2014;17(1):9-13.

22. Setiadi. Konsep Dan Proses Keperawatan Keluarga. Yogyakarta: Graha Ilmu; 2008.

23. Nasir, A. \& Muhith, A. Dasar-Dasar Keperawatan Jiwa Pengantar dan Teori. Jakarta: Salemba Medika; 2011.

24. Suprajitno. Asuhan Keperawatan Keluarga Aplikasi dalam Praktik. Jakarta: Buku Kedokteran EGC; 2008.

25. Febriani, R.N. 2008. Penderita Gangguan Jiwa Terus Meningkat. [Diakses 19 Januari 2017]. Available at: http://www.antarajateng. com/detail/index.php?id=2145.

26. Muntiaroh., Eny, H \& Wulandari, M. Gambaran Pengetahuan Masyarakat Tentang Skizofrenia di RT 6 Wilayah Kerja Puskesmas Juanda Kelurahan Air Hitam. Prosiding Konferensi Nasional PPNI Jawa Tengah 4-6 Maret 2013; Jawa Tengah.

27. Trisnowati, H. Pemberdayaan Masyarakat untuk Pencegahan Faktor Risiko Penyakait Tidak Menular (Studi pada Pedesaan di Yogyakarta). Media Kesehatan Masyarakat Indonesia. 2018;14(1)17-25. 